\title{
O Programa Nacional de Inclusão de Jovens: Projovem: uma análise entre a proposta oficial e a experiência vivida em Goiânia
}

Márcia Friedrich*

Claudio R. Machado Benite**

Anna M. Canavarro Benite ${ }^{* * *}$

\section{Resumo}

A escolarização brasileira é fruto da história desta sociedade em seus modelos econômicos, politicos e sociais ditados por relações de poder de grupos ideologicamente dominantes. Neste contexto, a Educação de Jovens e Adultos (EJA) segue à margem, portanto, emerge a constituição de saberes docentes inerentes a esta modalidade de ensino. Esta é uma pesquisa participante que objetiva tecer reflexões sobre a EJA, voltando o debate às questões relacionadas a políticas públicas, especificamente, ao Programa Nacional de Inclusão de Jovens: Educação, Qualificação Profissional e Ação Comunitária (Projovem), em Goiânia. Apresentamos a caracterização deste tecido social através de seus egressos e também a análise crítica da proposta pedagógica. Considerações sobre a relação entre proposta oficial e a experiência vivida concluem nossa apresentação dos resultados.

Palavras-chave: Educação de Jovens e Adultos. Políticas públicas. Projovem.

\section{The National Youth Inclusion - Projovem: an analysis between the officially proposed and the lived experience in Goiânia}

\section{Abstract}

The Brazilian school system is the result of the history of this society in its economical, political and social models and is dictated by the relationship of the groups ideologically dominant. In this context, the Education of Youth and Adults

\footnotetext{
* Mestre em educação em ciências e matemática, Laboratório de Pesquisas em Educação, Química e Inclusão (LPEQI ), Universidade Federal de Goiás(UFG), Professor da rede municipal de educação de Goiânia. E-mail: marcia.friedrich@gmail.com

** Doutorado em química, LPEQI, UFG; Docente da Universidade Estadual de Goiás (UnUCET /UEG). Email: claudio.benite@ueg.br

**** Doutora em Ciências, LPEQI, UFG. E-mail: anna@quimica.ufg.br
} 
(EJA) follows the margin, therefore, emerges the constitution of knowledge inherent in teaching this modality of teaching. This is a participatory research that aims to make reflections on EJA, and the debate goes back to issues related to public policy, specifically to the inclusion of the National Program for Youth: Education, Vocational Training and Community Action (Projovem) Goiânia. We report the characterization of the social designed scheme through its graduates and also the critical analysis of its pedagogical proposal. Considerations on the relationship between the official proposal and the lived experience conclude our presentation of results.

Keywords: Education for Youth and Adults. Public Policy. Projovem.

\section{El Programa Nacional de inclusión de jóvenes (Projovem): un análisis entre el proyecto oficial y su experiencia en Goiânia - Brasil Resumen}

La escolarización brasileña es el resultado de la historia de esta sociedad en sus modelos económicos, políticos y sociales dictados por las relaciones de poder de los grupos ideológicamente dominantes. En este contexto, la Educación de Jóvenes y Adultos (EJA) sigue al margen, por lo tanto, emerge la constitución de los saberes docentes inherentes a este tipo de enseñanza. Se trata de una investigación participativa que tiene como objetivo la reflexión sobre la EJA, centrar el debate sobre cuestiones relacionadas con la política pública, específicamente el Programa Nacional de Inclusión de Jóvenes: Educación, Formación Profesional y Acción Comunitaria (Projovem) Goiânia. Se presenta la caracterización del tejido social a través de sus graduados, así como el análisis crítico de la propuesta pedagógica. Consideraciones sobre la relación entre la propuesta oficial y la experiencia concluyen esta presentación de resultados. Palabras clave: Educación para Jóvenes y Adultos. Políticas públicas. Projovem.

\section{Políticas públicas e Educação de Jovens e Adultos (EJA): um grande nó}

A discussão que apresentamos aqui busca identificar em que medida os instrumentos legais, referentes à EJA, possibilitam a concretização da reivindicação de uma política pública destinada aos excluídos historicamente da escola e criam as condições para que a especificidade desta população seja respeitada. Pretendemos examinar as atuais políticas públicas de EJA com o sentido de avaliar se satisfazem determinados referenciais da teoria pedagógica dessa modalidade de educação.

Em princípio, cabe explicitar que a acepção de política pode ser entendida como práxis, espaço, governo e sistema de regras. É uma palavra de origem grega, que vem do termo polis, que diz respeito à cidade, urbanidade, civilidade. A política 
solicita uma difícil concessão: que os indivíduos e os grupos saiam de si mesmos, se moderem, se ultrapassem e se coloquem na perspectiva dos demais. 0 grande desafio para a política é criar as condições para que os indivíduos passem da defesa dos interesses particulares para a construção e a defesa do interesse geral. Tal perspectiva nos leva à sua acepção, em primeiro lugar, como práxis que nos remete à sua compreensão como resultado das ações humanas criando as condições para sua existência na sociedade (SANTIAGO, 2004).

Uma reflexão sobre a educação aponta para a educação de adultos como resultado da ineficácia do Estado em garantir, por meio de políticas públicas adequadas, a oferta e a permanência da criança e do adolescente na escola. Conforme discutido por Haddad e Di Pierro (2000, p. 126):

[...] Este tem sido o caminho da educação de jovens e adultos, que ao sair da preocupação central do Ministério da Educação como educação fundamental pensada para todos, passou para os espaços das políticas compensatórias da filantropia e do mercado. "Não que tais programas não tenham espaço por suas caracteristicas de inovação e atendimento, no entanto, não podem ser consideradas substitutas da ação do Estado, mas sim complementares.

Impulsionado pela necessidade de prestar contas à comunidade internacional sobre os indices de analfabetismo, o Estado brasileiro buscou encontrar soluções imediatas para resolver o problema instalado e erradicar o analfabetismo. Manifestações populares apareceram indo de encontro às iniciativas do Estado. Com isso, a divergência de ideias sobre um mesmo tema, formas de abordagens e iniciativas pedagógicas com traço marcante do grupo interessado surgem na tentativa de instituir programas que solucionem os problemas do grupo cultural em questão. Por parte do Estado fica clara a intencionalidade política, a busca do analfabeto para cumprir suas obrigações eleitorais etc. Por sua vez, os movimentos populares caracterizam-se pela lutas por seus direitos, conscientização cidadã e luta por direitos civis. Estes podem ainda ser descritos pela busca da valorização cultural com ênfase nos aspectos culturais locais de cada região e a busca da solução de problemas locais de interesse do grupo.

As duas últimas décadas foram marcadas por processos de reformas da matriz neoliberal que resultaram na desconstrução dos compromissos ético-políticos e sociais firmados pelo Estado na Constituição de 1988. Tais processos corresponderam às demandas para a inserção do país, de forma associada e subalterna, no atual quadro hegemônico mundial. É assim, nos marcos da nova ordem econômica internacional e de adaptação do Estado brasileiro à concepção de Estado mínimo, que é empreendida a reforma educacional brasileira. É no bojo dessa problemática que se situam as atuais politicas destinadas à EJA (RUMMERT; VENTURA, 2007). 
Neste contexto, observamos os investimentos em EJA por meio de programas e ações voltadas para o desenvolvimento integral do cidadão, tais como o Programa Nacional de Inclusão de Jovens: Educação, Qualificação Profissional e Ação Comunitária (Projovem), que representa uma aposta das políticas públicas de governo no sentido de criar condições necessárias para que seja desfeita uma sucessão de incoerências e o rompimento com a reprodução de desigualdades sociais (SALGADO, 2007).

0 Projovem enfatiza em sua concepção ser "Política de Juventude", portanto, cabe ressaltar que, nessa investigação, optamos por dialogar com a legislação e politicas de EJA, pela semelhança da faixa etária específica do Programa (18 a 24 anos) e pela dimensão "Educação" do mesmo remeter à conclusão do Ensino Fundamental. Assumido este pressuposto, defendemos que as práticas pedagógicas do Projovem permitem estabelecer diálogo com a modalidade EJA. Desta forma, a presente investigação apresenta uma reflexão sobre a relação entre a proposta pedagógica do Projovem (discurso oficial) e o "vivido", ou seja, a realidade deste grupo social em Goiânia.

\section{O Projovem Goiânia}

Para analisar a relação entre a proposta pedagógica do Programa (discurso oficial) e o "vivido", se faz necessário conhecer o programa, a sua estrutura, o seu processo de implantação e a sua proposta pedagógica.

0 Projovem é resultante de um estudo feito pelo Grupo Interministerial da Juventude. Este grupo constituiu-se com o propósito de elaborar um diagnóstico sobre a juventude brasileira tendo em vista a elaboração de uma política nacional para a mesma. 0 programa é considerado um componente estratégico da Política Nacional da Juventude do Governo Federal e foi implantado sob a coordenação da Secretaria Nacional da Juventude, ligada à Secretaria Geral da Presidência da República, estabelecendo parcerias com o Ministério da Educação, Ministério do Trabalho e Emprego e o Ministério do Desenvolvimento Social e Combate à Fome. 0 parecer favorável da Câmara de Educação Básica e do Conselho Nacional de Educação, como um curso experimental embasado no Artigo 81, da Lei de Diretrizes e Bases da Educação Nacional (BRASIL, 1996), possibilitou a certificação de conclusão do Ensino Fundamental e Qualificação Profissional em formação inicial (CONSELHO NACIONAL DE EDUCAÇÃO, 2006a).

0 Projovem foi legalmente instituído pela Lei no. 11.129 (BRASIL, 2005b) e regulamentado pelo Decreto $n^{\circ}$. 5.557 (BRASIL, 2005a). Assumindo caráter emergencial e experimental tem por finalidade a elevação do grau de escolaridade visando à conclusão do ensino fundamental, qualificação profissional em nivel de formação inicial voltada a estimular a inserção produtiva e cidadã e o desenvolvimento de ações comunitárias com práticas de solidariedade, exercício da cidadania e intervenção social (BRASIL, 2005b). 0 programa oferece ainda, como eixo de formação, aulas de informática enfatizando a inclusão digital e uma bolsa auxilio mensal condicionada, tanto à freqüência de 75\% do aluno às aulas quanto à entrega dos trabalhos obrigatórios solicitados pelos professores. 
0 Programa é destinado:

[...] a jovens com idade entre dezoito e vinte e quatro anos, que atendam, cumulativamente, aos seguintes requisitos: I. Tenham cursado, no mínimo, a $4^{\text {a }}$ série do Ensino Fundamental ou realizado estudos equivalentes, mas ainda não tenham concluído seus estudos no nível do Ensino Fundamental; e, II. Não tenham vínculo empregatício formal (CONSELHO NACIONAL DE EDUCAÇÃO, 2006a, p. 5).

De acordo com o projeto de criação, este Programa visa à reinserção do jovem à Educação, com o objetivo de incentivá-lo na busca de uma qualificação profissional e a participação em ações comunitárias para que o mesmo possa, então, melhorar significativamente sua condição social de excluído da escola e do mercado de trabalho.

Segundo as Diretrizes Curriculares Nacionais para a Educação de Jovens e Adultos (CONSELHO NACIONAL DE EDUCAÇÃO, 2006a), a Formação Básica deverá garantir as aprendizagens que correspondem às Diretrizes Curriculares Nacionais para o Ensino Fundamental e a certificação correspondente, bem como, ao mesmo tempo, fundamentar a Formação Profissional e a Ação Comunitária.

Por sua vez, a Qualificação Profissional inicial para o trabalho deverá possibilitar novas formas de inserção produtiva, com a devida certificação, correspondendo, na medida do possivel, tanto às necessidades e potencialidades econômicas locais e regionais, quanto às vocações dos jovens participantes do programa. Finalmente, a Ação Comunitária deverá resultar de um diagnóstico das necessidades locais e regionais, e promover a participação social cidadã (CONSELHO NACIONAL DE EDUCAÇÃO, 2006a).

\section{A estrutura do Programa}

Quanto à organização do espaço escolar, o Projovem é desenvolvido em núcleos que são compostos de cinco turmas (com o mínimo de vinte alunos por turma, conforme Resolução n. 3 (CONSELHO NACIONAL DE EDUCAÇÃO, 2006b) que devem funcionar diariamente em locais onde há espaços adequados disponiveis e, se possivel, próximos aos domicilios dos estudantes.

Os núcleos do Projovem Goiânia funcionam nas estruturas físicas das escolas municipais e, a cada oito núcleos, institui-se uma Estação da Juventude. Esta é o espaço de referência para os jovens, local de encontro (em Goiânia uma casa alugada para este fim) de busca de informação, de orientação e estudo. Nela são desenvolvidas atividades em grupo, eventos culturais e outras ações que favoreçam o processo formativo, a expressão cultural e a participação cidadã dos alunos. 
Figura 1 - Estrutura dos Núcleos do Projovem.

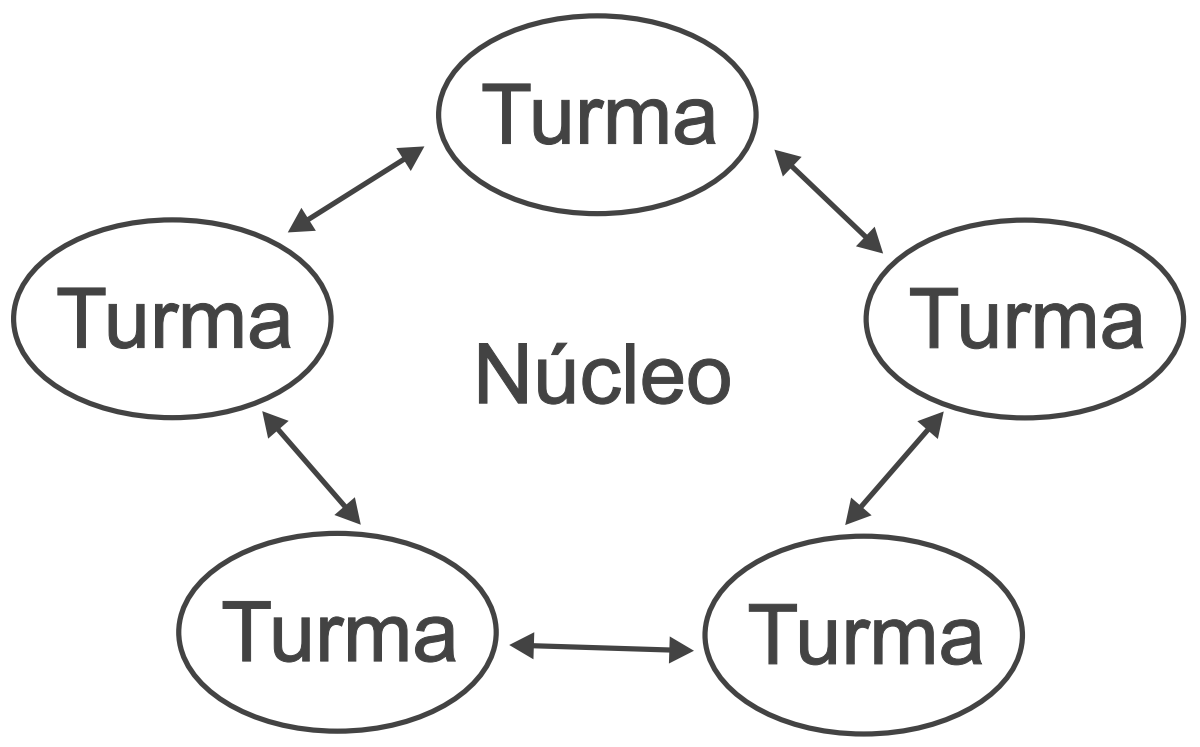

Fonte: Adaptado de Conselho Nacional de Educação (2006b).

Esses espaços servem, também, como ambiente de reunião, de formação dos gestores e docentes e de avaliação do programa. Neles foram instalados acervos multimídia e equipamentos que servem aos gestores e coordenadores do Projovem, bem como ao pessoal de apoio administrativo.

Os computadores têm acesso à rede de dados do Programa e receberam diversos sistemas que atendem às necessidades da administração e da gestão pedagógica. As estações também são equipadas com um laboratório de informática que fica à disposição dos alunos e professores.

\section{O Projovem Goiânia e seu processo de implantação}

No município de Goiânia, o Projovem foi implantado através de convênio firmado com o governo federal e é administrado por quatro secretarias: a Secretaria Municipal de Educação, responsável pela estrutura gerencial do programa como um todo; a Secretaria da Juventude, na articulação das políticas públicas da juventude, a Secretaria do Desenvolvimento Econômico responsável pela articulação da qualificação profissional eà Secretaria Municipal de Assistência Social coube a responsabilidade do gerenciamento da ação comunitária.

0 quantitativo de alunos referente às três entradas ${ }^{1}$ do programa em Goiânia está disposto segundo a Tabela 1.

1 A duração de cada entrada é de doze meses. 
Tabela 1 - Quantitativo de Alunos do PROJOVEM - Goiânia, 2006/2007.

\begin{tabular}{c|c|c|c|c|c}
\hline \multirow{2}{*}{ ENTRADA } & & \multicolumn{4}{|c}{ QUANTITATIVO DE } \\
\cline { 3 - 6 } & $\begin{array}{c}\text { ESTAÇÃO } \\
\text { JUVENTUDE }\end{array}$ & INSCRITOS & MATRICULADOS & $\begin{array}{c}\text { CONCLUINTES } \\
\text { da Escolarização }\end{array}$ & $\begin{array}{c}\text { CONCLUINTES } \\
\text { da Escolarização } \\
\text { +ualificação } \\
\text { Profissional }\end{array}$ \\
\hline $1^{\text {a }}$ & EJ $^{*}-I$ & 3858 & 646 & 152 & 121 \\
\hline & EJ-II & & 872 & 181 & 155 \\
\hline $2^{\text {a }}$ & Subtotal & & 1518 & 333 & 276 \\
\hline & EJ-IB* & 1815 & 376 & 107 & 59 \\
\hline $3^{\text {a }}$ & EJ-IIB & & 510 & 124 & 124 \\
\hline TOTAL & Subtotal & & 886 & 231 & \\
\hline
\end{tabular}

Fonte: Coordenação Administrativa do PROJOVEM - Goiânia.

* EJ - Estação da Juventude

" Campo de Coleta de Dados

A primeira turma do Projovem em Goiânia foi implantada em 2 de fevereiro de 2006, e a segunda turma, que constitui a amostra pesquisada desta investigação, em 7 de julho de 2006.

Cada núcleo possui um grupo composto por cinco professores especialistas (graduados em Matemática, Ciências Humanas - Geografia e História, Ciências Naturais, Língua Portuguesa e Língua Estrangeira), um professor de Qualificação Profissional e um assistente social para trabalhar a ação comunitária. Para a Qualificação Profissional, foram contratados professores graduados em Nutrição, Engenharia, Arquitetura, Publicidade, Administração e Design de Moda referentes às áreas que se destacam no contexto de Goiânia: alimentação, construção e pequenos reparos, telemática e vestuário.

As inscrições dos alunos interessados em participar do programa Projovem foram feitas por telefone gratuitamente junto à coordenação nacional, e os inscritos, encaminhados para a Coordenação Municipal para efetivarem sua matrícula.

Inicialmente, em Goiânia, o Projovem funcionou em 11 núcleos distribuídos nos bairros onde a demanda por matrículas foi maior. Os alunos não-moradores destes bairros foram convidados a escolher um núcleo mais próximo da sua casa.

\section{A Proposta Pedagógica}

0 princípio fundamental do Projovem é o da integração entre a Educação Básica, a Qualificação Profissional e a Ação Comunitária, tendo em vista a promoção da 
equidade considerando as especificidades de seu público: a condição juvenil e a imperativa necessidade de superar a situação de exclusão em que se encontram os jovens, no que se refere aos direitos à educação e ao trabalho. Entende-se ainda que o acesso a esses direitos, assim como a outros direitos universais, só será pleno quando a sociedade e, particularmente, os segmentos privados de direitos reconhecerem-se e assumirem-se como cidadãos ativos, conscientes do seu direito e da necessidade de lutar por eles (BRASIL, 2006b).

A proposta de currículo integrado no Projovem e a adoção do mesmo em uma perspectiva de cooperação interdisciplinar e interdimensional enfoca o desenvolvimento de saberes, conhecimentos, competências, valores e práticas de solidariedade compativeis com a vida moderna, ações de aspectos importantes para os jovens que moram nas grandes cidades. As questões sociais, trabalho, saúde, participação cidadã foram articuladas de maneira que se entrelacem em um currículo integrado para uma melhor orientação e direcionamento do jovem cidadão. 0 Programa prevê o princípio de que a aprendizagem acontece quando os conhecimentos são organizados e requerem uma reflexão de que a educação seja contextualizada e integrada, considerandose 0 aluno como sujeito protagonista de sua formação humana e cidadã.

0 programa tem carga horária de 1.600 horas (1.200 presenciais e 400 nãopresenciais), a serem cumpridas ao longo de 12 meses ininterruptos. As horas presenciais estão divididas em Formação Escolar (800 horas), Qualificação Profissional (350 horas) e Ação Comunitária (50 horas).

A formação está organizada em quatro Unidades Formativas (UF) (período correspondente a um trimestre do programa), cada uma com seu respectivo eixo estruturante composto por cinco temas integradores para cada UF: UF-I - juventude e cidade (Ser jovem hoje; Morar na cidade grande; Violência urbana e defesa do cidadão; Qualidade de vida na cidade; Meio ambiente e saneamento), UF - II- juventude e trabalho (Ser jovem aprendendo e trabalhando; Produzir e consumir na cidade; A violência e o trabalho; Qualidade de vida e trabalho; Trabalho e meio ambiente), UF- III -juventude e comunicação (A importância da comunicação para a vida e o trabalho dos jovens; Comunicação: espaço de interação dos jovens cidadãos ou espaço de alienação?; Comunicação: proteção contra a violência urbana?; Como a comunicação influi na qualidade de vida do jovem?; Comunicação, globalização e cidadania) e UF-IV - juventude e cidadania (Ser, de fato, um cidadão completo já é uma realidade para o jovem brasileiro?; Dá para ser feliz morando na cidade grande?; Violência urbana combina com cidadania?; Ser aluno do Projovem: uma experiência cidadã?; Que responsabilidade tem o jovem cidadão na proteção do meio ambiente e do planeta?). Assim, os diferentes componentes curriculares se integram através dos eixos estruturantes que estabelecem, entre si, a progressão das aprendizagens (BRASIL, 2007). 
A proposta pedagógica integrada do Projovem, segundo seu Manual de Orientações Gerais (SALGADO, 2007), é definida com uma abordagem interdisciplinar, articulando conhecimentos de várias áreas com as experiências de vida dos jovens. Os conteúdos são propostos como ferramentas de inclusão social e a seleção dos mesmos direciona para a formação de cidadãos conscientes e capazes de mudar suas posturas diante de fatos e problemas da vida moderna.

0 currículo do PROJOVEM abrange os diferentes aspectos do ser humano em sua interação com a cultura e a sociedade contemporâneas [...]. Muitas vezes se espera que um currículo integrado não tenha disciplinas distintas e se constitua unicamente pela análise de problemas vinculados à realidade (SALGAD0, 2007, p. 32).

A integração interdimensional e interdisciplinar constitui um trabalho em que é preciso não somente currículo articulado em rede, mas garantia de tempo e espaço específicos para essa formação. Os educadores especialistas do Projovem, neste caso, atuam como professores orientadores da aprendizagem (segundo uma orientação construtivista, grifo nosso), trabalhando com os alunos na elaboração das sinteses interdisciplinares, do Plano de Ação Comunitária (PLA) e do Projeto de Orientação Profissional (POP). As três atividades criam oportunidades adequadas para que o jovem construa sua subjetividade, fazendo interagir a pessoa humana, o trabalhador, o estudante e o cidadão (BRASIL, 2007).

Os temas integradores trabalhados no decorrer do desenvolvimento do programa interligam-se ao longo das unidades formativas. Esse aspecto está relacionado ao caráter interdisciplinar adotado pelo programa: a apropriação dos conteúdos pelo jovem, não em si mesmos, mas como suporte para o desenvolvimento das habilidades de diferentes tipos, dos valores e das atitudes, por meio da ressignificação de elementos sociais e culturais.

A Qualificação Profissional (QP) no Projovem - Goiânia, na primeira e na segunda turma, ocorreu por meio de convênio com o Serviço Nacional de Aprendizagem Industrial (Senai). Durante os doze meses os jovens tiveram aulas de $\mathrm{QP}$, no núcleo, chamadas de Formação Técnica Geral, previstas na matriz curricular e no horário regular, que eram ministradas por profissionais contratados para este fim. Ao término das aulas no núcleo, os alunos foram encaminhados ao Senai para a QP propriamente dita, com carga horária de $200 \mathrm{~h}$, distribuídas de acordo com a disponibilidade dos profissionais e espaço físico do órgão contratado, sendo que, neste período, os alunos também foram acompanhados pelos professores de QP dos núcleos. 


\section{Configuração da pesquisa}

Aqueles a quem nos dirigimos, para perguntar, para pesquisar, para educar ou para criar algo juntos, são pessoas (como um jovem que não sabe se é melhor seguir na escola ou "cair na rua" de uma vez), são pares de pessoas (como um casal), famílias nucleares (o casal e mais dois filhos), são grupos domésticos (a família nuclear sozinha, ou acrescida de um "pai da esposa"), são grupos de idade (como as "turmas" de meninos ou de meninas, na escola), são grupos de interesse (como "time de futebol"), são equipes de trabalhos (como a de uma "turma de operários da construção civil"), são, coletivamente, instituições sociais (como a associação de pais e mestres de uma escola), as diferentes unidades individuais ou coletivas que compõem e configuram, entre fios e tons diferentes, a urdidura do cotidiano daquilo a que damos o nome de "tecido social". Desta forma, a pesquisa serve à criação do saber e o saber serve a interação entre saberes (BRANDÃO, 1984).

Neste contexto, emerge a pesquisa participante (PP) como "uma tentativa de instituir alternativa ao paradigma dominante de pesquisa, bem como de providenciar acesso ao saber por parte dos marginalizados" que pode ser descrita de modo mais comum como atividade integrada que combina investigação social, trabalho educacional e ação (TANDON, 1981, p. 22 apud DEMO, 2004, p. 53).

Assumido este pressuposto, esta investigação atuou no sentido do desenvolvimento de uma estratégia de participação deste grupo (os egressos do Projovem - Goiânia) situado histórica e socialmente no presente processo de produção coletiva de conhecimento em torno de suas vivências e interesses. Aqui se instaura a "investigação social".

Os egressos do Projovem - Goiânia da EJ-I-B (Estação Juventude I-B) foram convidados a participar desta pesquisa visando a contribuir para uma possivel reprogramação das atividades educativas do programa de acordo com suas necessidades e interesses. Aqui se reconhece o trabalho educacional em questão e, é neste momento que se explicita o compromisso central da "investigação social e educativa": a investigação/observação militante (BORDA, 1978; FREIRE, 1987), o que neste caso, se define pela relação do pesquisador, que foi professora de Matemática do programa ao longo do ano de 2007, com o grupo social: "Só se conhece em profundidade alguma coisa da vida da sociedade ou da cultura, quando há um envolvimento entre o pesquisador e aquele que ele investiga" (BRANDÃO, 1984, p. 8). Completando o ciclo da atividade integrada (pesquisa participante, investigação social, investigação educativa e ação) intencionou-se a ação: a pesquisa torna-se ação no sentido de possibilitar a comunidade assumir seu próprio destino. 
Resumidamente, no tocante $\dot{a}$ ação, pretendeu-se propor que, uma vez conhecida a antítese presente na proposta de formação do Projovem, se possa indicar caminhos para redimensionamento da proposta, pois "o mérito da PP não está só em recolocar o âmbito da prática mas igualmente admitir sua fundamentação teórica" (DEMO, 2004).

\section{Sobre a escolha da amostra pesquisada}

Apoiamo-nos em Paiva (2006) na adoção de critérios para escolha da amostra pesquisada. Estes são apresentados abaixo conforme sua justificativa:

a) Abrangência nacional - independentemente da proposta/concepção, a amostra, isto é, o programa, deveria realizar-se em vários estados da federação, por um ou mais organismos, envolvendo largo número de sujeitos, o que quase sempre contraria as lógicas da EJA, de pequenas experiências localizadas.

b) Permanência da organização na rede pública - consideramos o fato da amostra estar institucionalizada como modalidade de atendimento no sistema de ensino. 0 Projovem, mesmo no âmbito de Programa, instala-se pelo tempo necessário à sua implantação e execução, na rede pública do município.

c) Necessidade de oferecer resposta específica, considerando a realidade de uma dada região ou de determinados sujeitos - procuramos verificar a consistência de propostas que se orientavam pela ação de EJA com formato próprio, considerando as especificidades sociais, culturais, políticas e históricas de uma determinada região.

\section{Do instrumento de coleta de dados}

0 instrumento utilizado para a coleta de dados foi o questionário, escolha esta que se constituiu pela utilização da linguagem escrita. Ao responder o questionário, o pesquisado precisa usar a linguagem escrita e, esta, precisa transferir a linguagem interior para o exterior (VYGOTSKY, 2000 apud BENITE; BENITE, 2008). Devemos ainda ressaltar que a linguagem escrita é carregada de intencionalidade, e que é a consciência e a interação que orientam a escrita. Seu emprego, portanto, exige uma ação mais abstrata e intelectualizada. Foram distribuídos 59 questionários, dos quais retornaram 45.

0 instrumento de coleta de dados foi elaborado visando à coleta de informações sobre o "vivido", ou seja, a realidade do grupo social pesquisado. A estruturação do mesmo foi orientada pela busca de blocos de questões que permitissem obter informações:

a) sobre a caracterização do perfil social do pesquisado, constituindo o primeiro bloco de questões;

b) sobre a proposta pedagógica, isto é, as três dimensões do programa: Educação, Qualificação Profissional e Ação Comunitária, constituindo respectivamente o segundo, o terceiro e o quarto bloco; 
c) sobre as impressões gerais sobre o programa tais como acesso e significação pessoal deste, constituindo o quinto bloco.

Os sujeitos da coleta de dados foram os jovens concluintes da Estação Juventude I da segunda entrada do Projovem - Goiânia. Nesta etapa, para esta Estação Juventude, matricularam-se 376 jovens, dos quais, 107 fizeram o exame de certificação final, composto pelas dimensões da Educação Básica e Ação Comunitária. Destes 59 concluíram o Programa com o curso de Qualificação Profissional, com as três dimensões do programa. Dos concluintes, 45 retornaram o questionário de pesquisa.

Este quantitativo pode ser considerado satisfatório uma vez que, nas classes de EJA, tratamos de alunos adultos, homens e mulheres, providos de uma competência comunicativa, com base predominante na oralidade (linguagem falada) satisfatória para os ambientes familiares nas esferas privadas da vida social. Desta forma, responder ao questionário significa um salto para o mundo grafocêntrico (linguagem escrita) e a inserção ativa no mundo letrado (SOUZA; MOTA, 2007). Igualmente importantes a veracidade e a simplicidade com que os jovens responderam ao questionário.

\section{Do discurso à prática}

Passaremos agora a apresentar nossa discussão dos resultados. Porém, por questões de espaço, estaremos abordando neste artigo o bloco de questões referentes às impressões gerais acerca do Projovem que caracteriza o quinto bloco de questões do instrumento de coleta de dados.

\section{Sobre as impressões gerais acerca do Programa: algumas vozes...}

Serão apresentados a seguir os resultados oriundos do quinto bloco de questões (Quadro 1).

Quadro 1- Perguntas referentes ao quinto bloco de questões.

\begin{tabular}{|l|l|}
\hline \multirow{0}{*}{ O Programa } & $\begin{array}{l}\text { Quais aspectos você achou mais interessante no PROJOVEM?Se você não tivesse } \\
\text { o auxilio financeiro teria conseguido fazer o curso?Fale sobre a experiência no } \\
\text { PROJOVEM, o que este significou na sua vida?Você considera que programas } \\
\text { desta natureza são importantes para o desenvolvimento do país?É muito im- } \\
\text { portante para nós ouvir suas sugestões e/ou críticas sobre PROJOVEM. }\end{array}$ \\
\hline
\end{tabular}

Fonte: Os autores (2009).

A Tabela 2 apresenta as respostas relacionadas à primeira questão do bloco em discussão. 
Tabela 2 - Aspectos mais interessantes do PROJOVEM segundo o egresso.

\begin{tabular}{c|c}
\hline Aspectos & Número de respostas $^{*}$ \\
\hline Conhecimentos práticos relacionados ao trabalho & 10 \\
\hline Conhecimentos gerais & 21 \\
\hline Envolvimento social & 20 \\
\hline
\end{tabular}

Fonte: Os autores (2009).

*Alguns egressos marcaram duas alternativas.

0 interesse dos egressos pelos conhecimentos gerais e pelo envolvimento social remete à busca pela escolarização e inserção social. Porém, a escola, segundo Kuenzer (2002), constituiu-se historicamente como uma das formas de materialização da divisão e alienação.

Nesta ótica, as políticas assistencialistas configuram-se como uma forma de mascarar a desigualdade social instalada no decorrer da história. Em nome de desenvolvimento social, indices de universalização da educação e mão-de-obra qualificada buscam-se estratégias e atrativos à população jovem como incentivo para que o mesmo vá para a escola, como é 0 caso da oferta de bolsas como incentivo à entrada e permanência no Projovem.

Quando indagados quanto a esse auxílio financeiro ( $R$ \$ 100,00 por mês) oferecido pelo programa, 25 egressos afirmaram considerar de fundamental importância para a realização do curso:

A42: "Por que a situação não permitia".

A39: "Por que em geral o aluno que trabalha ganha pouco".

A33: "Por que não teria como pagar o transporte".

A31: "Estava desempregada e não teria condições de me dirigir até o núcleo".

A30: "Eu estava desempregada e minha mãe não teve condições de me dar o dinheiro".

A5 e A9: "Por que eu não trabalhava".

A20: "Por que o auxilio financeiro que ajudou nos meus gastos com materiais para trabalho e para o vale transporte".

A14: "Eu estava desempregada".

A13: "Por que não havia renda para o sustento da casa".

A12: "Por que moro longe recebo pouco do meu trabalho e ajudo muito em minha casa".

Os egressos relataram que utilizam o auxílio financeiro, principalmente, como fonte de renda ou para complementá-la. Estes resultados revelam que, ao se desobrigarem de encargos sociais, os governos neoliberais transferem responsabilidades (ao mercado e à sociedade). Estas ações não privilegiam o fortalecimento da cidadania, que "ao invés de direitos, retorna aos favores e à caridade, que não produz políticas universais, mas políticas compensatórias, verdadeiras "cestas básicas" de saúde, educação, previdência etc., para os mais pobres, privatizando tudo o mais" (CARVALHO, 1997, p.12). 
Desta maneira, motivados por uma política assistencialista e compensatória, os resultados parecem revelar que os egressos retornaram aos bancos escolares, lançando-se novamente em busca de conhecimento sistematizado no intuito de chegar ao seleto mercado de trabalho.

\section{A Relação Projovem/Egresso}

Apresentamos a seguir os resultados referentes às ultimas três perguntas do questionário que visam à coleta de elementos que permitam delinear a relação do egresso com o programa. Os resultados analisados geraram algumas categorias de análise que são expostas no Quadro 2 e serão discutidas a seguir.

Quadro 2 - Quadro de categorias de análise identificadas nas respostas dos egressos.

\begin{tabular}{|c|c|c|c|}
\hline $\begin{array}{l}\text { Categorias de Análise } \\
\text { Acesso à Escolarização }\end{array}$ & $\begin{array}{c}\text { Perguntas" } \\
1\end{array}$ & $\begin{array}{c}\text { No Respostas* }^{*} \\
16 \\
\\
14 \\
10\end{array}$ & $\begin{array}{l}\text { Exemplos de respostas } \\
\text { A20: "Foi uma experiência muito im- } \\
\text { portante na minha vida: me ajudou a } \\
\text { concluir meus estudos do Ensino fun- } \\
\text { damental [...]". } \\
\text { A30: "Sim. Por que tem muita gente } \\
\text { que não terminou os estudos [...]". } \\
\text { A21: "Continuação do projeto, ou seja, } \\
\text { a continuidade com o ensino médio". }\end{array}$ \\
\hline $\begin{array}{l}\text { Valorização pessoal } \\
\text { e inserção social }\end{array}$ & $\begin{array}{l}2 \\
3\end{array}$ & $\begin{array}{c}24 \\
20 \\
5\end{array}$ & $\begin{array}{l}\text { A42: "Voltei a pensar em estudar, a ter } \\
\text { garra e fazer novas amizades". } \\
\text { A12: "Com certeza, pois o jovem tem } \\
\text { uma chance de crescer na vida". } \\
\text { A31: "O PROJOVEM deve continuar } \\
\text { porque melhora a autoestima dos alu- } \\
\text { nos". }\end{array}$ \\
\hline Sujeito de direitos & $\begin{array}{l}2 \\
3\end{array}$ & 5 & $\begin{array}{l}\text { A12: "Aprendi que eu tinha direitos } \\
\text { que eu nem pensava que tinha: saúde, } \\
\text { educacaño [...]". } \\
\text { A29: "Simm. Porque as pessoas passam } \\
\text { a entender o que é errado e o que cer- } \\
\text { to, o que pode ou não, seus direitos". } \\
\text { A25: "Bom, a critica é que não recebi } \\
\text { minha bolsa mensal, recebi só a meta- } \\
\text { de do valor que eles falaram". }\end{array}$ \\
\hline $\begin{array}{l}\text { Vinculo com mundo } \\
\text { do trabalho }\end{array}$ & $\begin{array}{l}1 \\
2\end{array}$ & $\begin{array}{l}13 \\
16\end{array}$ & $\begin{array}{l}\text { A9: "Estar mergulhada na minha pro- } \\
\text { fissão". } \\
\text { A41: "Sim. Porque ajuda os jovens a } \\
\text { ter uma chance no mercado de traba- } \\
\text { lho". } \\
\text { A22: "Fornecer indicação do curso } \\
\text { profissionalizante para o emprego". }\end{array}$ \\
\hline
\end{tabular}

Fonte: Adaptado de Benite (2009).

\#Legenda para as perguntas utilizadas no Quadro:

1 - Fale sobre a experiência no PROJOVEM, o que este significou na sua vida? 2-Você considera que programas desta natureza são importantes para o desenvolvimento do pais? Por quê? 3-É muito importante para nós ouvir suas sugestões e/ou críticas sobre PROJOVEM.

*É importante esclarecer que as respostas podem se enquadrar em mais de uma categoria. 


\section{Acesso à escolarização}

Considerando que, no discurso oficial, o acesso ao ensino fundamental se encontra praticamente universalizado, agora o grande desafio consiste no incremento da escolaridade dos jovens através de políticas de incentivo à frequência escolar e à escolarização de jovens e adultos, o que caracteriza o Projovem. No que diz respeito ao acesso a escolarização, Haddad e Di Pierro $(2000$, p. 117) enfatizam que: "[...] cabe às políticas públicas a educação escolar de jovens e adultos e, desta forma, cabe a escola cumprir o objetivo de prover e/ou repor a escolarização regular, e atualizar conhecimentos".

Ainda segundo os autores, a escola deve cumprir seus objetivos:

a) em primeiro lugar, provendo a educação regular como observado na resposta a seguir:

A32: "Foi ótimo participar deste curso, significou para mim a conclusão da oitava série".

Igualmente na resposta de A21 apresentada no quadro de categorias de análise identificadas nas respostas dos egressos.

A21: "Continuação do projeto, ou seja, a continuidade com o ensino médio".

b) em segundo lugar, repondo a escolarização regular como identificado na resposta a seguir:

A39: "Foi uma porta que se abriu para que eu tomasse impulso e terminasse o ensino fundamental".

0 aluno A30 reforça a resposta apresentada no quadro de categorias de análise identificadas nas respostas dos egressos.

A30: "Sim. Porque tem muita gente que não terminou os estudos [...]".

c) e, por último, atualizando os conhecimentos como identificado na resposta a seguir:

A45: "Melhorou bastante a minha leitura, para conversar e interagir com as pessoas [...]".

A20 corrobora com o argumento apresentado no quadro de categorias de análise identificadas nas respostas dos egressos.

A20: "Foi uma experiência muito importante na minha vida: me ajudou a concluir meus estudos do Ensino fundamental [...]". 


\section{Valorização pessoal e inserção social}

Encontra-se, no contexto definido anteriormente, a busca de iniciativas, tais como o Projovem, que através de propostas pedagógicas promovam não somente a escolarização continuada dos jovens, mas que garantam condição juvenil, sem desprezar as questões emblemáticas da geração, possibilitando-os à invenção de novos sentidos para a sua existência e participação social (SILVA, 2004).

De acordo com Sposito (2000), Haddad e Di Pierro (2000) e Sirvent (2005), o crescimento da participação social inicia uma fase de interação com a educação e, particularmente, com as práticas escolares. As novas formas de participação na vida social promovem a possibilidade de construção de uma escola para jovens e adultos que participe no desenvolvimento de uma cidadania plena, ultrapassando as necessidades de habilitação para o trabalho e procurando significados que incidam sobre as identidades culturais (conforme identificado no quadro de categorias de análise), a subjetividade e a participação na esfera pública.

\section{Sujeito de direitos}

Os direitos do homem e do cidadão e a cidadania são históricos, resultam das relações e dos conflitos sociais em determinados momentos da história de um povo. Esse percurso da construção da cidadania do povo brasileiro não é linear. Segundo Gadotti (1989) "as relações e articulações entre as diversas esferas transformam o indivíduo em ser social, com modos de agir e pensar" em:

a) sua singularidade, como identificado na resposta a seguir:

A8: "Uma critica é a qualidade da minha merenda".

Percebe-se a mesma ênfase na resposta de A25 apresentada no quadro de categorias de análise identificadas nas repostas dos egressos. 0 ser como individual em seus anseios e necessidades.

A25: "Bom, a critica é que não recebi minha bolsa mensal, recebi só a metade do valor que eles falaram".

b) ou como membro da coletividade, como observado na resposta a seguir:

A14: "O curso é uma oportunidade de abrir novos caminhos de exigir meu espaço na comunidade".

$E$, de modo semelhante nas respostas de $A 12$ e A29 apresentadas no quadro de categorias de análise identificadas nas repostas dos egressos. 
A12: "Aprendi que eu tinha direitos que eu nem pensava que tinha: saúde, educação [...]".

A29: "Sim. Porque as pessoas passam a entender o que é errado e o que certo, o que pode ou não, seus direitos".

A educação entra neste contexto como uma contribuição decisiva na sua formação profissional, cultural e no entendimento do seu tempo e espaço próximo ou mais distante.

\section{Vínculo com o mundo do trabalho}

A participação dos adolescentes e jovens no mercado de trabalho tem sido analisada, muitas vezes, em associação com a discussão da sua situação educacional, em consequência de um cenário de crescentes exigências em termos de escolaridade para o exercício das atividades laborais (DEMO, 1993).

Desta forma geram-se:

a) expectativas e as atitudes com relação ao trabalho, como identificado na resposta a seguir:

A35: "Este programa abriu uma oportunidade para melhorar de vida, sendo qualificado melhor para o trabalho".

0 alunos A9 e A41 reforçam a afirmação apresentada no quadro de categorias de análise identificadas nas repostas dos egressos.

A9: "Estar mergulhada na minha profissão".

A41: "Sim. Porque ajuda os jovens a ter uma chance no mercado de trabalho".

b) expectativas e as atitudes com relação ao emprego e ao desemprego, como identificado na resposta a seguir:

A20: "Eu aprendi uma profissão na área de telemarketing e espero obter um emprego de operador de micro ou helpdesk".

Da mesma forma, o aluno A22 demonstra o mesmo pensamento como consta no quadro de categorias de análise.

A22: "Fornecer indicação do curso profissionalizante para o emprego".

Estas respostas parecem revelar a busca da inserção profissional que proporciona aos sujeitos desta investigação, ocasião de se abrir, de ter acesso a um novo 
universo cultural e relacional suscetivel de proporcionar novos pontos de referência. A partir dessa reflexão, é possível evidenciar um ponto de convergência entre o proposto e o vivido. Assim, ressalta-se o fato de como é difícil retirar o dominador dos nossos discursos. "São eles e ao mesmo tempo são o outro introjetado neles, como consciência opressora" (FREIRE, 1987, p. 35).

\section{Considerações finais}

A reflexão sobre a EJA no Brasil permitiu desvelar muitas relações contraditórias e conflituosas. Este percurso é marcado por direções desencontradas, sem políticas públicas eficientes para a elucidação de uma, atual, modalidade de inclusão escolar que sempre seguiu à margem do sistema educacional. Ocupando ingênuas inferências, a EJA foi se inserindo na legislação oficial através da luta de alguns ícones da educação popular como Paulo Freire.

Os resultados permitem constatar a contradição e os conflitos vivenciados pelos jovens, demonstrando a fragilidade de políticas públicas implementadas sem o devido planejamento de ações necessárias e que vão ao encontro dos reais anseios dos jovens. Por outro lado, a busca do jovem pela formação visa à imediata inserção no mercado de trabalho impulsionado pelos modos de produção e consumismo vigentes no sistema capitalista e neoliberal que estamos inseridos. No tocante às propostas de governo no campo da educação, esta investigação se constitui como um importante instrumento de avaliação para esta proposta, já que esta é uma iniciativa recente e pouco se tem discutido sobre ela.

As categorias de análise que emergem do discurso do egresso nos remetem exatamente às três dimensões (Educação, Qualificação Profissional e Ação Comunitária) do Programa. Fato este que parece demonstrar que o objetivo da proposta pedagógica integradora não foi alcançado, uma vez que nestes resultados as categorias (acesso à escolarização, valorização pessoal e inserção social, sujeito de direitos e vínculo com o mundo do trabalho) se apresentaram desconexas e desarticuladas da proposta inicial, ou seja, como pedaços isolados da constituição do egresso.

Em sintese, umas das dificuldades de se atrelar o discurso à prática numa ação de natureza social é que nesta, o outro lado (a prática) é constituído por pessoas, sujeitos sociais dotados de suas especificidades. Deste modo, esta investigação procurou conhecer estes sujeitos por meio de seu discurso. Nossos resultados intentam permitir delinear estratégias que trabalhem para superar estas dicotomias, possibilitando uma produção coletiva de conhecimentos em torno das vivências, interesses e necessidades deste grupo que foi situado histórica e socialmente. Ademais, reivindica a imersão prática, pois estes sujeitos não precisam apenas estudar seus problemas, precisam, sobretudo, ser capazes de enfrentá-los e resolvê-los. 


\section{Agradecimentos}

A Fundação de Amparo à Pesquisa do Estado de Goiás (FAPEG) e ao Conselho Nacional de Desenvolvimento Científico e Tecnológico (CNPq), pelo fomento concedido ao desenvolvimento desta pesquisa.

\section{Referências}

BENITE, A. M. C.; BENITE, C. R. M. 0 computador no ensino de química: impressões versus realidade: em foco as escolas públicas da Baixada Fluminense. Ensaio: Pesquisas em Educação em Ciências, Belo Horizonte, v. 10, n. 2, 2008.

BENITE, C. R. M. Uma discussão curricular em um grupo interdisciplinar de professores do ensino médio. Dissertação (Mestrado)-Programa de Pós-Graduação em Ciências e Matemática, Universidade Federal de Goiás, Goiânia, 2009.

BORDA, F. 0. Por la praxis: el problema de como investigar la realidad para transformarla. In: SIMPOSIO MUNDIAL DE CARTAGENA, 1978, Bogotá. Critica y política em ciencias sociales. Bogotá: Ed. Punta de Lanza, 1978. v. 1, p. 209-249.

BRANDÃO, C. R. Repensando a pesquisa participante. São Paulo: Brasiliense, 1984.

BRASIL, Decreto ${ }^{\circ}$. 5.557, de 5 de outubro de 2005. Regulamenta o Programa Nacional de Inclusão de Jovens - PROJOVEM. Diário Oficial da União, Brasília, DF, Brasília, DF, 6 out. 2005a.

BRASIL. Lei no. 9.394, de 20 de dezembro de 1996. Estabelece as diretrizes e bases da educação nacional. Diário Oficial [da República Federativa do Brasil], Brasilia, DF, 23 dez. 1996. Seção 1, p. 27833-27841.

BRASIL. Lei no 11.129, de 30 de junho de 2005. Institui o Programa Nacional de Inclusão de Jovens - PROJOVEM. Diário Oficial da União, Brasília, DF, Brasilia, DF, 1 jul. $2005 b$.

BRASIL. Secretaria Nacional de Juventude. Relatório de atividades 2006. Brasília, DF, 2007.

CARVALHO, M. C. A. Participação social no Brasil hoje. São Paulo: Instituto Pólis, 1998. (Pólis Papers, n. 2). Disponível em:<http://www.polis.org.br/obras/ arquivo_169.pdf>. Acesso em: 7 mar. 2012. 
CONSELHO NACIONAL DE EDUCAÇÃO (Brasil). Câmara de Educação Básica. Parecer CNE/CEB nº. 37, de 7 de julho de 2006. Diretrizes e procedimentos técnico-pedagógicos para a implementação do PROJOVEM - Programa Nacional de Inclusão de Jovens. Diário Oficial da União, Brasilia, DF, 4 ago. 2006a.

Resolução CNE/CEB n. 3, 15 de agosto de 2006. Aprova as Diretrizes e procedimentos técnicopedagógicos para a implementação do ProJovem Programa Nacional de Inclusão de Jovens, criado pela Lei no 11.129, de 30/7/2005, aprovado como "Projeto Experimental", nos termos do art. 81 da LDB, pelo Parecer CNE/CEB nº 2/2005. Diário Oficial da União, 16 ago. 2006b. Seção 1, p. 8.

DEMO, P. Participação é xonquista: noções de política social participativa. 2. ed. São Paulo: Cortez, 1993.

DEMO, P. Pesquisa participante: saber pensar e intervir juntos. Brasília, DF: Liber Livro Ed., 2004.

FREIRE. P. Pedagogia do oprimido. 17. ed. Rio de Janeiro: Paz e Terra, 1987.

GADOTII, M. Educação e poder: introdução à pedagogia do conflito. 9. ed. São Paulo: Cortez: Autores Associados. 1989.

HADDAD, S.; DI PIERRO, M. C. Escolarização de jovens e adultos. Revista Brasileira de Educação, rio de Janeiro, n. 14, p. 108-130, 2000.

KUENZER, A. Z. Exclusão excludente e inclusão excludente: A nova forma de dualidade estrutural que objetiva as novas relações entre educação e trabalho. In: LOMBARDI, J. C., et. al. (Org.). Capitalismo, trabalho e educação. Campinas, SP: Autores Associadas, 2002. p. 77-88. (Coleção educação contemporânea).

PAIVA, J. Tramando concepções e sentidos para redizer a Educação de Jovens e Adultos. Revista Brasileira de Educação, Rio de Janeiro, v. 11, n. 33, p. 519-539, 2006.

RUMMERT, S. M.; VENTURA, J. P. Políticas públicas para educação de jovens e adultos no Brasil: a permanente (re)construção da subalternidade: considerações sobre os Programas Brasil Alfabetizado e Fazendo Escola. Educar em Revista, Curitiba: Ed. UFPR, n. 29, p. 29-45, 2007.

SALGADO, M. U. C. (Org.). Manual do educador: orientações gerais. Brasília, DF: MEC, Programa Nacional de Inclusão de Jovens, 2007. (Coleção Projovem). 
SANTIAG0, R. A. A gestão da Educação de Jovens e Adultos no Brasil. 2004. $261 \mathrm{f}$. Tese (Doutorado em Educação)-Faculdade de Educação, Universidade Estadual de Campinas, Campinas, SP, 2004.

SILVA, N. "Ser adulto": alguns elementos para a discussão deste conceito e para a formação de professores de jovens e "adultos". Revista Millenium, Viseu, PT, n. 29, jun. 2004. Repositório Científico do Instituto Politécnico de Viseu.

SIRVENT, M. T. La educación de jóvenes y adultos frente al desafio de los movimientos sociales emegentes em Argentina. Revista Brasileira de Educação, Rio de Janeiro, n. 28, 2005.

SOUZA, J. F.; MOTA, K. M. S. 0 silêncio é de ouro e a palavra é de prata? Considerações acerca do espaço da oralidade em educação de jovens e adultos. Revista Brasileira de Educação, Rio de Janeiro, v. 12, n. 36, 2007.

SPOSITO, M. P. Algumas hipóteses sobre as relações entre os movimentos sociais, juventude e educação. Revista Brasileira de Educação, Rio de Janeiro, n.13, 2000.

Recebido em: 12/09/2009

Aceito para publicação em: 11/11/2011 